\title{
Psychological aspects of pain
}

\author{
H. MERSKEY \\ M.A., D.M., D.P.M. \\ Physician in Psychological Medicine, \\ The National Hospital for Nervous Diseases, Queen Square, London, W.C.1
}

INTEREST in pain never ceases. The present survey is intended to indicate some of the main current psychiatric approaches to the elucidation and treatment of pain syndromes.

\section{Significance of pain}

'Unprofessional persons are always accustomed to associate together the ideas of pain and danger; yet the physician well knows that the most fatal maladies are often the least painful' (Williams, 1852). The author of this remark was an astute physician who distinguished between the pains of angina pectoris and neuralgia, by which he meant what would now be called effort syndrome or psychogenic pains. Despite such views, pain is normally held to be prima facie evidence of physical disease (Stengel, 1960). To anyone trained in biology and especially in neuro-anatomy and physiology it is natural to think of pain as evidence of some physical disturbance. Yet, as Williams and Stengel have pointed out, there is much to suggest that pain is often a sign of psychological disturbance. This is particularly true if headache is included in the discussion. As a symptom, it is very common, particularly in psychiatric patients; thus $6.6 \%$ of all the patients in a general practice had headache (Carne, 1967) and $8.7 \%$ of a population of army recruits undergoing selection (Weider et al., 1944), while its frequency rose to $48.7 \%$ in cases rejected by the U.S. services on psychiatric grounds. For this and other reasons it has been firmly suggested (Friedman et al., 1962) that most headaches are psychological in origin. Further, in considering pain as a symptom affecting any part of the body, Klee et al. (1959) found that $61 \%$ of a series of psychiatric patients had pain and Spear (1964) obtained similar figures. In a medical clinic Devine \& Merskey (1965) found that $38 \%$ of the patients with pain and $40 \%$ of those without pain were there because of psychological illness. These findings tend to confirm what the experienced clinician has always recognized: that something which is called 'pain' is a result of emotional disturbance in at least a substantial minority of patients. A review of the literature (Merskey \& Spear, 1967b) suggests that this is probably true in many different branches of medicine and surgery.

It has also long been recognized that emotional factors could abate the severity of pain or abolish it altogether, despite the presence of extensive wounds. Montaigne (1580) wrote 'We feel one cut from the surgeon's scalpel more than ten blows of the sword in the heat of battle'. Baron Larrey (cit. Chertok, 1959) observed a similar indifference to wounds by soldiers during the Napoleonic wars and comparable observations have been made by many others, either about battle (Mitchell, Morehouse \& Keen 1864) or other exciting situations (Kraepelin, 1903 ; Rivers, 1920). In particular, Beecher (1956) showed in a systematic study that wounded soldiers, for whom the wound represented an honourable release from danger, were far less in need of analgesics than civilians with lesions of comparable size, for whom the lesions represented a largely unwelcome disturbance of their normal lives. Some of the difference between soldiers and civilians may be due to different effects from injuries due to high-speed missiles as compared with surgery. There are indications that high-speed injuries are less painful than others (Livingston, 1966) but this cannot account for all the situations reported. Thus far it can be said with certainty that psychological factors quite often cause pain and frequently augment its severity. They may also serve to abate or abolish it even in the presence of extensive physical trauma. These considerations have an important bearing on what we mean by pain.

It is a commonplace experience to hear doctors talking of pain arising at nerve-endings, passing along pain fibres, travelling up the spinothalamic tracts and reaching higher centres. Walters (1963) points out, in effect, that no such thing happens. Certainly noxious stimulation affects the activity of these parts-although not 
perhaps so specifically as we used to think (Weddell, 1962 ; Noordenbos, 1959 ; Melzack \& Wall, 1965). But pain is always a psychological event. It is something we talk about as part of our experience. As Walters indicates, the impulses in the pain fibres and tracts 'are no more the pain than the visual impulses from the retina are the perceptual fields of color and pattern that present to us when our eyes are open'. Szasz (1957), in an important theoretical discussion from the psychoanalytic aspect, takes the same view. It is therefore preferable always to talk of 'noxious stimulation' rather than painful stimulation, despite the convenience of the latter expression.

This argument may seem abstract, but ignoring it leads to trouble. It leads to doctors telling patients, who are convinced they have pain, that they do not have it because no organic disorder has been found. Most clinicians are familiar with the unfortunate and avoidable consequences of making this error. If so, they may well find it helpful to agree that the patient has an experience which to him is pain, even though no causative physical mechanism seems likely. It may be easier to do so in the light of the evidence that psychological factors are so common as causes for pain. It has accordingly been argued (Merskey, 1964 ; Merskey \& Spear, $1967 \mathrm{a}, \mathrm{b})$ that an operational definition of pain should be adopted as follows: 'An unpleasant experience which we primarily associate with tissue damage or describe in terms of such damage, or both'. This emphasizes the relationship of pain with the experience of damage to the body and, without making any assumption as to causes, it provides a framework whereby the statements of patients who describe bodily experiences like burning, aching, stabbing, etc., can be assessed, investigated and compared. It follows that by 'psychogenic pain' one should mean pain whose causes are mainly or wholly psychological and by 'organic pain' one means pain whose principal causes are physical. There is no necessary difference between these cases in the subjective experience which the sufferer attempts to describe. In each case it is felt as being like the experience of damage to the body. As a corollary to these views it is worth mentioning that 'mental pain' is a metaphorical expression and does not connote any experience of bodily damage. It is thus distinct from 'psychogenic pain'.

\section{Mechanisms of psychogenic pain}

Three principal mechanisms are recognized in the psychological aetiology of pain. The first, which is relatively rare, is the occurrence of pain as a hallucination, in association either with schizophrenia or endogenous depression (Michaux, 1957 ; Schneider, 1959 ; Bleuler, 1960). Most psychiatrists have seen one or two instances of this. In schizophrenia the pain is usually one of a number of other delusional experiences, e.g. that the body is changing in size or being interfered with or that electricity or radar is being directed at the patient. Similarly, in endogenous depression any such hallucinatory pain, occurring independently of a physical mechanism, is usually part of a well-defined syndrome. Occasionally with these illnesses pain is the sole definite symptom and the diagnosis can only be made after some fresh development has occurred in the illness.

The second mechanism or group of mechanisms in psychogenic pain is represented by pain due to muscle tension where that tension itself is due to psychological causes. Another variant on the same theme is the pain of vascular distension, as in migraine, where the process can be initiated by psychological factors.

Sound evidence has been available for some years to suggest that pain often originates by such psychosomatic processes (Wolff, 1948). This evidence has not been seriously challenged. Indeed, investigators have continued to present data (Malmo \& Shagass, 1949 ; Malmo, Shagass \& Davis, 1951) that anxiety gives rise to local muscle contraction which, if persistent, causes pain. The possible chemical mediator of these processes is still in doubt (Elkind \& Friedman, 1962 ; Wolff, 1966). Perhaps some of these mechanisms have been used too widely in explanation since demonstrable myographic differences only account for part of the variance in the experimental studies quoted, but it is easy to see how tempting this type of explanation must be, particularly when many headaches and other pains are undoubtedly relieved by reassurance, relaxation and sedatives.

The third main possible psychological mechanism is that of conversion hysteria. The concepts of hysteria and of the unconscious owe much to Freud (Breuer \& Freud, 1893-95) but did not originate with him. Brodie (1837) of Brodie's abscess fame, said that 'In upper-class women' four-fifths of joint-pains were hysterical, and claimed that 'fear, suggestion and unconscious simulation were the primary factors'. This is quite representative of other comments scattered through the literature of the last two centuries (cf. Veith, 1965).

It is of particular interest that, in the four women whom Freud described fully in his first 
essays on hysteria, pain was a prominent symptom. However, the actual frequency of hysteria as a cause of pain is very difficult to assess. Although the validity of the diagnosis of hysteria has been disputed (Slater, 1965) and it certainly carries hazards, there is some evidence that hysterical mechanisms are important in the development at least of persistent pain in psychiatric patients. What is of considerable importance is the idea that a pain may arise not as a result of any physiological process but by an intelligible chain of psychological events. There is also good evidence that there is a group of hypochondriacal patients whom most psychiatrists would recognize as having hysteria and in whom pain is a prominent symptom (Guze \& Perley, 1963). It has to be noted that in these cases with intractable hypochondriasis the current sources of emotional conflict are sometimes few and the theory that a conflict exists has to be based upon assumptions about the patients' earlier experiences, particularly in childhood, which are not always demonstrable. But the pattern of the symptoms and the patient's personality can indicate a resemblance with those hysterical symptoms whose causes are more accessible.

Perhaps the most striking illustration of pain as a symptom solving unconscious conflicts and serving to symbolize unconscious attitudes is the couvade syndrome. This word, derived from the Basque, couver, meaning to sit on eggs, describes the behaviour of fathers who may act as if suffering from labour pains or lie in bed after their wives' childbirth while the women continue with their normal occupations. Such behaviour occurs in many cultures, is well known to anthropologists and was discussed in some detail by Reik (1914). It is not so attractive to the father as it may sound since many rules of abstinence may have to be observed by him. The term has also been used to cover pains and other physical complaints without organic basis which are found in expectant fathers. As such, the couvade syndrome is still known to occur in Indians of many different social levels (Bardhan, 1965a, b), in mining communities (Dennis, Henriques \& Slaughter, 1965 ; P. Crann, personal communication, 1965) and in modern urban society (Curtis, 1955; Trethowan \& Conlon, 1965). The latter authors gave a useful description of some cases and showed a significant incidence of such symptoms in a survey. The point about this syndrome, relevant to our present discussion, is again to emphasize the psychogenesis of pain as a symptom felt to occur in the body and yet not owing its existence to any physiologic mech- anism. Having reiterated this possibility we can now consider the particular psychiatric diagnoses with which pain is most associated.

\section{Pain due to psychiatric illness}

It has been indicated that schizophrenia may be accompanied by hallucinations of pain but this is rare. In several other common psychiatric illnesses pain abounds. Thus it is a frequent symptom in neurotic depression, in anxiety states and in hysteria. It does not have such a marked association with obsessional neurosis, the organic confusional states, subnormality, psychopathic personality nor, as a spontaneous symptom, with the sexual perversions.

In many instances of course the pain considered is usually transient and responds to suitable reassurance with or without sedation. Or, once it has been established that the problem is psychiatric, attention is directed away from the symptom of pain while appropriate treatment is instituted and the pain then usually resolves with the illness.

The largest series of psychiatric patients with pain has been described by Walters (1961) who reported on 430 cases seen for intractable pain. As in other series, the head and neck were the commonest site. Walters distinguished three separate ways in which psychological factors can evoke pain, as follows:

1. Psychogenic magnification of physical pain.

2. Psychogenic muscular pain (as a result of tension).

3. Psychogenic regional pain.

He recommends this last term in place of the older one of hysterical pain because these patients do not conform to the traditional picture of calm and contented hysteria. They are often depressed and anxious even though they may have some form of conversion symptom.

The writer considers this classification only partly satisfactory. The first category is acceptable but lends itself too readily to the concepts of a small, real 'organic' pain which is 'exaggerated' for psychological reasons. It must be acknowledged, however, that no more satisfactory term has been offered for this common situation which the category describes. The second category is acceptable but the third is the least satisfactory. Pain which fulfills the third set of criteria may be capable of inclusion under the other two. Walters' article is well worth attention, however, for the clinical data it contains, e.g. the finding that the descriptions of pain are often not dramatic (a point made also by Wilson, 1938, Gittleson, 1961, and Devine 
\& Merskey, 1965). In additon, it gives a realistic and helpful picture of the way in which a combination of both general medical and psychiatric techniques of assessment is necessary and the ways in which psychiatric treatment is beneficial.

At the other end of the scale there has been a very large number of papers describing the psychodynamics and treatment of individual patients with chronic pain of psychological origin. Hart (1947) and Merskey \& Spear (1967b) list most of these and discuss their implications. The authors considered generally see the condition as some form of hysteria but do not offer systematic or comparative evidence in favour of their views. They also emphasize the association of pain with resentment and guilt.

Menninger (1938) gave more evidence of the masochistic attitudes of these patients and stressed the frequency with which they underwent unnecessary operations. Greenacre (1939) made the same points in a very telling description of a single case.

A further contribution has been made by Engel $(1951,1959)$ who described twenty patients (nineteen of them women) with facial pain. He regarded his subjects as suffering from an hysterical conversion symptom but he emphasized that they possessed a 'masochistic' character structure, showing many varieties of self-punitive behaviour, i.e. behaviour which repeatedly placed them in unhappy situations. Like Menninger and Greenacre he stressed the frequency with which his patients underwent unnecessary operations. He also noted the gusto with which they would tolerate pain due to physical causes. This approach requires some change in the commonly held idea that psychiatric patients are more 'sensitive' to pain, even though that idea is undoubtedly partly justified. In his later paper, Engel (1959) named this type of patient the pain-prone patient. Although there is no direct comparison with other patients the volume of evidence which Engel describes supports his argument well.

In order to try and clarify which psychiatric patients were liable to pain, to obtain more data on them and to obtain some check on the foregoing theories, the writer (Merskey, 1964, 1965a, b) examined a series of 100 psychiatric patients with persistent pain and compared them with a stratified control sample of sixty-five patients who denied having pain in association with their illness. It was found that the commonest association of persistent pain in psychiatric illness was with hysteria, anxiety neurosis and neurotic depression. Although there were patients with endogenous depression and with schizophrenia who had persistent pain it was relatively less common with those diagnoses. Whilst the material was not confined like Engel's to patients with facial pain this provides systematic support for his general views. A study by Spear (1964) both confirms and complements these findings. Spear had studied psychiatric patients with and without pain but had included patients whose pain was not persistent. $\mathrm{He}$, too, found pain to be associated relatively more often with diagnoses of hysteria and anxiety than with the psychoses.

\section{Personality characteristics and pain}

It has been indicated that certain attitudes, frequently unconscious, have been attributed to patients with pain of psychological origin. These attitudes include hostility, resentment and guilt. Knopf (1935a, b) was one of the first to suggest that these traits occurred in those migrainous subjects who were liable to have their headache precipitated by psychological factors. Wolff (1948) supported these views. Largely similar attitudes have, however, been attributed not only to patients with pain in any part of the body but also to patients with asthma, eczema, dysmenorrhoea, ulcerative colitis and the other supposedly psychosomatic illnesses as well as to a number of frank psychiatric illnesses. It therefore seems desirable to know whether these particular factors are more pronounced in patients with psychogenic pain than in others. There is no doubt that they are prominent in some instances and that this is sometimes due to mutual antagonism developing between patients and doctors, as a vivid paper by Bender (1964) bears witness. Spear (1964) looked for the expression of overt or covert hostility and found no difference between psychiatric patients with pain and those without. Similarly, the writer (Mersky, 1965b) found no difference in actual acts of aggression in such groups. Merskey did find, however, that spoken expressions of resentment were more common in his patients with pain. In four out of thirty instances this resentment was directed exclusively at doctors, in nine at doctors and others impartially and in seventeen at others to the exclusion of doctors. Another study with positive results was made by Eisenbud (1937). During treatment of a man suffering from amnesia and headaches he concluded that this particular patient was unconsciously hostile to his father. Since this hostility was unacceptable to the patient's conscious mind he was liable to be made anxious and hence to develop con- 
version symptoms under any circumstance that might bring it to light. One such event was his father's admission to hospital and the headache this caused was relieved by abreaction under hypnosis which permitted a subsequent conscious adjustment to the problem. Eisenbud then conducted a careful series of experiments to test the hypothesis that unconscious hostility would cause headache, but not other unconscious conflict. He did this by inducing 'artificial complexes' under hypnosis. It turned out that hostile or aggressive complexes did have this effect in his patient but not erotic ones. The limited systematic evidence that is available does thus suggest that resentment and, to a lesser extent, hostility are specially relevant to the hysterical type of pain. But it is not clear whether hostility and guilt are markedly more relevant to pain than to other psychiatric and psychosomatic complaints.

Other characteristics to which pain has been related include low social class, low ordinal position in the family, frigidity, dysmenorrhoea and other psychogenic bodily complaints. In many studies, not just those concerned with pain, it has been shown that the chronic clinic attender or patient with persistent pain is of low social status-most characteristically from an economic level equivalent to social classes 3 and 4 of the Registrar-General's classification (Ruesch, 1946; Hollingshead \& Redlich, 1958 ; Srole et al., 1962 ; Gonda, 1962). This applies even when correction is made for selection factors as in the American epidemiological studies by Hollingshead \& Redlich and by Srole et al., and has been interpreted as meaning that the less sophisticated patients will tend to visit the doctor and express depression or emotional conflict in 'body language' rather than in psychological terms. Even this view has its limitations, however, for Baker \& Merskey (1967) taking all forms of pain-acute and chronic-found no social class-difference in the distribution of pain in patients in a semirural general practice. As to birth order, the claim that this is relevant (Gonda, 1962) has not been confirmed (Spear, 1964). Birth-order investigation in fact, while one of the most superficially attractive topics in psychiatric research, has produced sadly conflicting results. Frigidity, however, is traditionally associated with hysteria and seems likely to be relevant (Merskey, 1965b ; Kreitman et al., 1965). In regard to dysmenorrhoea neither Spear nor the writer found a significant excess of this symptom in patients with psychogenic pain but other work (e.g. Kessel \& Coppen, 1963) leaves little doubt that some association does exist between dys- menorrhoea and psychiatric illness and may be shown by different survey methods.

In summarizing this section it may be helpful to say that while there are numerous variations on the basic theme the most typical psychiatric patient with pain is a married woman of the working or lower-middle class, possibly once pretty and appealing, but never keen on sexual intercourse, now faded and complaining, with a history of repeated negative physical examinations and investigations, frank conversion symptoms in up to $50 \%$ of cases in addition to the pain, and a sad tale of a hard life; together with depression which does not respond to antidepressant drugs. But anyone who relies too literally on this pen-picture for the purpose of diagnosis does so at his own risk. It represents a statistical mode amongst the clinical patterns, from which actual patients will frequently diverge.

\section{Appendicectomy and neurosis}

Appendicectomy and neurosis is a problem of particular interest to the surgeon. Experienced surgeons (e.g. Hinton, 1948) and gynaecologists (e.g. Atlee, 1966) are prone to emphasize the importance of psychological causes of acute abdominal pain. Hinton indeed gives the following list of its causes:

(1) Anxiety neuroses with conversion symptoms or other psychogenic factors.

(2) Physiologic conditions such as painful ovulation.

(3) True organic diseases which require surgical care.'

Nevertheless, a history of appendicectomy has been reported as occurring frequently in patients with abdominal pain in association with neurotic illness (Crohn, 1930). Lee (1961), in a statistical study, concluded that there was an excess of such operations, especially in young women, and that some $7000-8000$ unnecessary appendicectomies were performed annually in England and Wales. Harding (1962) concluded that $39.6 \%$ of a series of 1300 appendices examined histologically were completely normal, and the proportion of normal appendices removed approached two-thirds in females aged between 11 and 20 years. Wallace, Loane \& Quinn (1963) obtained similar data and Ingram, Evans \& Oppenheim (1965) considered that unsatisfactory results were obtained in those patients who had had normal appendices removed.

Most of this could easily have been predicted in the light of a paper by Blanton \& Kirk (1947) where sixty-one patients were studied for 
the presence of psychological disturbance and organic pathology. Of forty-four patients with an organic pathology thirteen were emotionally disturbed. The remaining seventeen with normal appendices all had psychiatric conditions. A chisquare computation of these figures shows a significant association of neurosis and normal appendices at the level $P<0.001$. But the thirteen neurotics with diseased appendices highlight the clinician's problem. A similar but less urgent problem has been demonstrated by Apley (1959) in respect of children with recurrent abdominal pain. Here the experience of pain can clearly be seen to be a learnt response-often patterned on parental attitudes.

\section{Psychological theories of pain}

Spear (1966) points out that psychiatric work to date has led to the development of three main theories of pain. In the first it is suggested that pain is a consequence of hostility (Eisenbud, 1937; Weiss, 1947; Engel, 1951, 1956), in the second that pain arises in patients of a certain personality-type who use the complaint as a means of communication (Engel, 1958, 1959). Mention has already been made of these theories. The third approach comes from Szasz (1957) who argues that pain arises as a consequence of a threat to the integrity of the body. Here the body is regarded as an object of concern to the self. The threat may not be apparent to an outside observer and the pain will then be classed as 'psychogenic'. These theories are not mutually exclusive and are all wholly psychological, i.e. they attempt to deal with pain as a psychological event in relation to those other psychological events which cause it. The theory of Szasz, in particular, utilizes the Freudian concepts of ego, id and super-ego, the ego being the part of the mind which relates both to the forces of the other two systems and to external reality. Szasz suggests that the ego perceives the body as an object and postulates that pain arises when a threat to the body is perceived, either for objective reasons or for emotional ones. The question of whether the symptom is considered organic or functional depends on the observer's assessment of the reality of the threat to the body.

Once this assessment has been made the meaning of the symptom can be considered and it is postulated that this meaning may be interpreted at three levels of symbolization. At the first level the communications are facts having to do with the sufferer's experience of the bodily symptom. At the next level pain is used as a communication which requests help. This func- tion is always involved in any complaint of pain, the two levels being inextricably bound. Communication at the third level of symbolization is more complex and here pain can persist as a symbol of rejection, the repetition of the complaint may become a form of aggression and the continued experience of pain may serve to expiate guilt.

If these hypotheses are looked at together it would seem that Engel's views fit well as a subtheory within the system of Szasz. It has been seen that some of Engel's arguments have had factual confirmation. The same is true for Szasz's concepts. In particular it has been shown (Spear, 1966) that psychiatric patients with pain show more concern with their physical health and bodily state than others who do not experience pain as part of their illness; and this concern is wider than the single symptom of pain.

Perhaps the most important aspect of the theory of Szasz is that it emphasizes the communicative significance of pain. This is something long recognized and liable to be forgotten and re-discovered by successive generations of doctors. Further, while the reader who is unaccustomed to psychoanalytic models may have found the theory difficult to follow, it does have the merit of clarifying the logical status and semantics of pain. Anyone who has thoroughly absorbed Szasz's argument is thus less liable to make the sort of errors which Walters (1963) has criticized. As a practical corollary the theory of Szasz leads to an examination of the modes of description of pain and the function which these modes serve. Before doing so it should be mentioned that important current physiological theories of pain have been offered by Noordenbos (1959) and Melzack \& Wall (1965) and that these theories can be reconciled with the psychological ones (Merskey \& Spear, 1967b).

\section{Descriptions of pain}

Brain (1962) observed 'Our vocabulary for the description of pain is relatively poor and we tend to fall back on terms which describe a pain by describing the way in which it might have been produced, even though in the particular instance it has not been so produced. Thus we speak of pricking pain, stabbing pain, shooting pain, burning pain, bursting pain and so on'. The implication of damage to the body is obvious. Klein \& Brown (1965) found that $58 \%$ of patients in a medical clinic used metaphors of violence to describe their pain. Descriptions of this sort are bound to be somewhat dramatic. It is often said that psychiatric patients use 
bizarre terms when they complain of pain. Dana (1911) gave a long list of such unusual descriptions, e.g. 'a pain in the ovary when excited, helmet sensation, sensations of the body being filled and stuffed with pricking burrs and a pricking as of pine-needles sticking out of the scalp'. As indicated in the discussion of Walters' work this view is not entirely confirmed. Thus Devine \& Merskey (1965) found that only thirteen of 100 psychiatric patients with persistent pain (usually severe) gave notably bizarre descriptions of their pain and fifty-one gave very simple descriptions. The same authors noted in patients who attended a medical clinic that those with 'psychogenic' pain gave similar descriptions to those with 'organic' pain and some of the most odd descriptions were somatically strictly accurate, e.g. a patient with a rectal carcinoma spoke of a 'strong pain a few inches inside my seatdrawing the seat down as if I was going with it'. The worse a patient felt his pain to be, the more words and the more peculiar similes he used to describe it so that there was a statistically significant trend for patients who said their pain was severe to give more elaborate and complex descriptions of it than those who said their pain was mild. This after all is common sense. Severe pains will provoke far more attention than mild ones. The qualitative description of pain is thus likely to reflect the importance of the pain to the patient and how much it matters to him. It is an earnest of the degree of his concern-and not particularly likely to be a sign of its causation.

\section{Differentiation of causes of pain}

The qualitative description of pain is clearly an unreliable guide in differential diagnosis. The characteristics of pain of psychological origin which are most typical are as follows (Merskey \& Spear, 1967b): Pain of psychological illness has never apparently been shown actually to rouse a patient from sleep. It is usually continuous from day to day (except at night) or else lasts upwards of $1 \mathrm{hr}$. It often involves more than one area of the body and it is commonest in the form of headache and often bilateral and symmetrical. Apart from the tendency not to disturb sleep, none of these characteristics is exclusive.

The differentiation of causes thus still depends upon clinical skill in establishing the presence of a valid physical or psychiatric diagnosis. Clearly the presence of positive physical signs (e.g. tenderness, spasm) or other evidence of physical disease is helpful. Similarly, positive evidence of psychiatric illness, the presence of the characteristics just outlined, evidence of the relevant personality traits discussed earlier and an appropriate response to psychiatric treatment may also be helpful. There are times, however, when neither physician, surgeon nor psychiatrist can find reliable evidence of a particular illness to account for a patient's pain. In these circumstances the best course is to suspend judgement, continue observation and treat the patient empirically with non-addictive analgesics.

\section{Treatment}

Progress both in diagnosis and treatment of chronic pain has been fostered in several centres by 'Pain Clinics' (McEwen et al., 1965; Simpson et al., 1965). These rely for their operation on regular consultation between several specialists, usually anaesthetists, neurosurgeons, radiotherapists and psychiatrists. Their work is evidently fruitful, as might be expected, since each of these disciplines has contributed much that is useful to the treatment of chronic pain. Anaesthetists have made a special contribution by extensive studies of the placebo response and the comparative effects of different drugs, again showing how much the abatement of fear may reduce pain. The same point is well recognized by those concerned with the care of the dying (Hinton, 1967) and of women in childbirth (Read, 1943 ; Chertok, 1959).

It has long been thought that hypnosis would modify or abolish pain at operation. There is reason to believe (Barber, 1958a, b) that hypnosis is not a special trance state but rather a situation in which the subject accepts the possibility of various unusual changes in his behaviour and then produces them on the suggestion of the hypnotist. Thus Barber (1963) suggests that the records of operations under hypnosis sometimes point not to an absence of pain but to an unwillingness to state that pain was experienced. Pain as an experience is not absent but is denied; and there are no greater changes in the physiological responses to noxious stimulation than can be produced by direct suggestion without hypnosis (Barber \& Hahn, 1962). As a manoeuvre directed towards allaying anxiety, however, hypnosis is successful, like other methods of suggestion, in allaying even chronic pain (Dorcus. \& Kirkner, 1948; Butler, 1954 ; Barber, 1959).

Apart from these general factors the specific psychiatric treatment of pain is frequently successful. Normally this occurs where there is a well-defined condition responsive to standard psychiatric treatments, e.g. anti-depressant drugs or ECT for endogenous depression, sedation and 
some form of psychotherapy in neurotic illnesses Unfortunately, where there is a well-marked persistent hypochondriacal or hysterical attitude, without marked evidence of anxiety or depression, treatment is less helpful. Despite favourable reports of the use of ECT (Von Hagen, 1957) and anti-depressant drugs (Lance \& Curran, 1964 ; Lascelles, 1966) for chronic pain there is no really satisfactory evidence that these measures are helpful in the absence of a significant degree of anxiety or depression. Similarly, chlorpromazine which can be useful in central pain (Lassman, Moody \& Gryspeerdt, 1959) or in terminal carcinoma (Saunders, 1963) is rarely useful in pain of neurotic origin. Perhaps when it is effective this is because of its action upon the reticular activating system. Occasionally, the above treatments work to the surprise of the psychiatrist, but too rarely for him who hopes to treat all psychogenic pain with drugs, so that there remains a group of patients in which the psychiatric contribution is limited to helping the patient to bear with his infirmity and the physician to bear with his patient. These usually are the hypochondriacal patients for whom the diagnosis of hysteria seems appropriate.

With regard to leucotomy for pain, similar considerations obtain as with anti-depressant drugs or ECT. It has been generally accepted for some years that leucotomy is useful if there is much anxiety, tension or depression evident. The combined use of ECT and drugs, has, however, greatly reduced the frequency with which it is considered. To relieve pain (including that of carcinoma), in the absence of anxiety or depression, leucotomy must be extensive and will then cause undesirable personality changes. This may be acceptable in terminal illness.

Treatment by stereotaxic surgery may also be appropriate and from this Cooper (1965) has made a particularly illuminating contribution to the understanding of cerebral mechanisms of pain.

\section{Experimental psychology}

A substantial literature has accumulated on this topic showing the influence of emotions on the occurrence of pain. Numerous investigations both by this method and others followed the introduction of the Hardy-Wolff-Goodell dolorimeter for heat-pain (cf. Hardy, Wolff \& Goodell, 1940, 1952 ; Hall, 1953, Beecher, 1959 ; Kutscher \& Kutscher, 1957; Cheymol, Gay \& Duteuil, 1959a ; Cheymol et al., 1959b ; Smith, 1963, 1966 ; Truchaud, 1965 ; Wolff et al., 1966a, b ; Merskey \& Spear, 1967b). This is a field in which positive achievements have been made but in which opinion and emphasis has varied considerably. Dispute has particularly centred on the validity and interpretation of so called Pain Perception Thresholds and Pain Reaction Thresholds. The interested reader is referred to the references cited.

\section{Acknowledgments}

I wish to thank Dr R. Gwyn Evans and Dr E. G. Oram for helpful comments.

\section{References}

APLEY, J. (1959) The Child with Abdominal Pains. Blackwell Scientific Publications, Oxford.

AtleE, H.B. (1966) Acute and Chronic Iliac Pain in Women. Thomas, Springfield.

BAKER, J. \& Merskey, H. (1967) Pain in general practice. J. psychosom. Res. 10, 383.

BARBeR, T.X. (1958a) Hypnosis as perceptual cognitive restructuring: II. Post-hypnotic behaviour. J. clin. exp. Hypnos. 6, 10.

Barber, T.X. (1958b) The concept of hypnosis. J. Psychol. 45, 115.

BARBER, T.X. (1959) Toward a theory of pain: relief of chronic pain by pre-frontal leucotomy, opiates, placebos and hypnosis. Psychol. Bull. 56, 430.

BARBER, T.X. (1963) The effects of 'hypnosis' on pain. Psychosom. Med. 25, 303.

Barber, T.X. \& HahN, K.W. (1962) Physiological and subjective responses to pain-producing stimulation undeP hypnotically-suggested and waking-imagined 'analgesia응 J. abnorm. soc. Psychol. 65, 411.

Bardhan, P.N. (1965a) The fathering syndrome. Arme Forces med.J. 20, 200.

Bardhan, P.N. (1965b) The couvade syndrome. Brit. $j$ Psychiat. 111, 908.

BEECHER, H.K. (1956) Relationship of significance of wound to the pain experienced. J. Amer. med. Ass. 161, 1609.

BEECHER, H.K. (1959) Measurement of subjective responses. Quantitative Effects of Drugs. Oxford University Press, New York.

BENDER, B. (1964) Seven angry crocks. Psychosomatics, 5, 225.

Blanton, S. \& KIRK, V. (1947) A psychiatric study of 61 appendicectomy cases. Ann. Surg. 126, 305.

BLEULER, E. (1960) Lehrbuch der Psychiatrie, 10th edn. Springer, Berlin.

BRAIN, LORD (1962) Presidential address in Keele \& Smith (1962).

Breuer, J. \& FreUd, S. (1893-95) Studies on hysteria. Complete Psychological Works of Freud. Standard Edition, Vol. 2. Hogarth Press, London, 1955.

BRODIE, B. (1837) Lectures illustrative of certain nervous affections, No. 2, London. Cit. Zilboorg, G. \& Henry, G. W., A History of Medical Psychology, Allen \& Unwin, London, 1941.

BUTLER, B. (1954) The use of hypnosis in the care of the cancer patient. Cancer, $7,1$.

CARNE, S.J. (1967) Headache. Brit. med. J. ii, 233.

CHERTOK, L. (1959) Psychosomatic Methods in Painless Childbirth (Transl. D. Leigh). Pergamon Press, London.

Cheymol, J., GAY, Y. \& DuTEuil, J. (1959a) Des différents tests proposés pour l'étude d'un analgésique. Thérapie, 14, 210.

Cheymol, J., Montagne, R., Dallon, S., Paeile, C. \& DuteuIL, J. (1959b). Contribution au test de la stimulation électrique de la dent du lapin pour l'étude expérimentale des analgésiques. Thérapie, 14, 350. 
COOPER, I.S. (1965) Clinical and physiologic implications of thalamic surgery for disorders of sensory communication. I. Thalamic surgery for intractable pain. J. neurol. Sci. (Amst.), 2, 493.

CroHN, B.B. (1930) The psychoneuroses affecting the gastrointestinal tract. Bull. N.Y. Acad. Med. 6, 155.

Curtis, J.I. (1955) A psychiatric study of 55 expectant fathers. U.S. Armed Forces med. J. 6, 937.

DANA, C.L. (1911) The interpretation of pain and the dysaesthesias. J. Amer. med. Ass. 56, 787.

Dennis, N., Henriques, F. \& Slaughter, C. (1956) Coal is our Life. Eyre \& Spottiswoode, London.

DeVINe, R. \& MERSKeY, H. (1965) The description of pain in psychiatric and general medical patients. J. psychosom. Res. 9, 311.

DoRCUS, R.M. \& KIRKNER, F.J. (1948) The use of hypnosis in the suppression of intractable pain. J. abnorm. soc. Psychol. 43, 237.

EISENBUD, J. (1937) The psychology of headache. Psychiat. Quart. 11, 592.

Elkind, A.H. \& Friedman, A.P. (1962) A review of headache: 1955 to 1961 . I-III. N.Y. St.J. Med. 62, 1220, 1444, 1649.

ENGEL, G.L. (1951) Primary atypical facial neuralgia. An hysterical conversion symptom. Psychosom. Med. 13, 375.

ENGEL, G.L. (1956) Studies of ulcerative colitis: IV. The significance of headaches. Psychosom. Med. 18, 334.

Engel, G.L. (1958) 'Psychogenic' pain. Med. Clin. N. Amer. 42, 1481 .

ENGEL, G.L. (1959) 'Psychogenic' pain and the pain prone patient. Amer. J. Med. 26, 899.

Friedman, A.P., Finley, K.H., Graham, J.R., Kunkle, C.E., OstFeld, M.O. \& WolfF, H.G. (1962) Classification of headache. Special report of the Ad Hoc Committee. Arch. Neurol. 6, 173.

Gittleson, N.L. (1961) Psychiatric headache: a clinical study. J. ment. Sci. 107, 403.

GoNDA, T.A. (1962) The relation between complaints of persistent pain and family size. J. Neurol. Neurosurg. Psychiat. 25, 277.

GREENACRE, P. (1939) Surgical addiction-a case illustration. Psychosom. Med. 1, 325.

Guze, S.B. \& Perley, M.J. (1963) Observations on the natural history of hysteria. Amer. J. Psychiat. 119, 960.

HAGEN, K.O. von (1957) Chronic intolerable pain. J. Amer. med. Ass. 165, 773.

Hall, K.R.L. (1953) Studies of cutaneous pain: a survey of research since 1940. Brit. J. Psychol. 44, 281.

HARDING, H.E. (1962) A notable source of error in the diagnosis of appendicitis. Brit. med. J. ii, 1028.

HARDY, J.D., WolfF, H.G. \& GoOdell, H. (1940) Studies on pain. A new method for measuring pain threshold: observations on spatial summation of pain. J. clin. Invest. $19,649$.

HaRdy, J.D., Wolff, H.G. \& Goodell, H. (1952) Pain Sensations and Reactions. Williams \& Wilkins, Baltimore.

Hart, H. (1947) Displacement, guilt and pain. Psychoanal. Rev. 34, 259.

Hinton, J.W. (1948) The surgical significance of acute abdominal pain. Calif. Med. 69, 418.

Hinton, J. (1967) Dying. Penguin Books, Harmondsworth.

Hollingshead, A.B. \& Redlich, F.C. (1958) Social Class and Mental Illness: A Community Study. Wiley, New York.

IngRaM, P.W., Evans, G. \& OPPenheim, A.N. (1965) Right iliac fossa pain in young women; with appendix on the Cornell Medical Index Health Questionnaire. Brit. med.J. ii, 149.

KeEle, C.A. \& Smith, R. (1962) The Assessment of Pain in Man and Animals. U.F.A.W., Livingstone, Edinburgh.

KesSEL, N. \& COPPEN, A. (1963) The prevalence of common menstrual symptoms. Lancet, ii, 61 .
Klee, G.D., Ozelis, S., Greenberg, I. \& Gallant, L.J. (1959) Pain and other somatic complaints in a psychiatric clinic. Maryland St. med. J. 8, 188.

KleIN, R.F. \& BRown, W.A. (1965) Pain as a form of communication in the medical setting. Unpublished abstract.

Knighton, R.S. \& Dumke, P.R. (1966) Pain: Henry Ford Hospital International Symposium. Churchill, London.

KNOPF, O. (1935a, b) Preliminary report on personality studies in thirty migraine patients. J. nerv. ment. Dis. 82, $270,400$.

Kraepelin, E. (1903) Allgemeine Psychiatrie, 7th edn. Barth, Leipzig.

Kreitman, N., Sainsbury, P., Pearce, K. \& Costain, W.P. (1965) Hypochondriasis and depression in out-patients at a general hospital. Brit. J. Psychiat. 111, 607.

KutsCher, A.H. \& Kutscher, N.W. (1957) Evaluation of the Hardy-Wolff-Goodell pain threshold apparatus and technique. Int. Rec. Med. 170, 202.

LanCE, J.W. \& CuRran, D.A. (1964) Treatment of chronic tension headache. Lancet, i, 1236.

LASCElles, R.G. (1966) Atypical facial pain and depression. Brit. J. Psychiat. 112, 651.

Lassman, P.L., Moody, J.F. \& GryspeerdT, G.L. (1959) Central pain due to cerebral ischaemia. Folia psychiat. néerl. 62, 34.

LEE, J.A.H. (1961) Appendicitis in young women. Lancet, ii, 815.

Livingston, W.K. (1966) Silas Weir Mitchell and his work on causalgia. Pain: Henry Ford Hospital International Symposium (Ed. by R. S. Knighton and P. R. Dumke), p. 561.

Malmo, R.B. \& Shagass, C. (1949) Psychologic study of symptom mechanisms in psychiatric patients under stress. Psychosom. Med. 11, 25.

Malmo, R.B., Shagass, C. \& Davis, J.F. (1951) Electromyographic studies of muscular tension in psychiatric patients under stress. J. clin. Psychopath. 12, 45.

MCEWEN, B.W., DE WILDE, F.W., DWYER, B., WOOdForde, J.M., Bleasel, K. \& Connelley, T.J. (1965) The pain clinic. Med. J. Aust. 52, 676.

Melzack, R. \& WAll, P.D. (1965) Pain mechanisms: a new theory. Science, 150, 971 .

MenNinger, K.A. (1938) Man against Himself. Harcourt \& Brace, New York.

MERSKeY, H. (1964) An investigation of pain in psychological illness. D.M. thesis, Oxford.

MerSKey, H. (1965a) The characteristics of persistent pain in psychological illness. J. psychosom. Res. 9, 291.

MERSKeY, H. (1965b) Psychiatric patients with persistent pain. J. psychosom. Res. 9, 299.

Merskey, H. \& SPeAR, F.G. (1967a) The concept of pain. J. psyschosom. Res. 11, 59.

Merskey, H. \& Spear, F.G. (1967b) Pain: Psychological and Psychiatric Aspects. Baillière, Tindall \& Cassell, London.

Michaux, L. (1957) Les aspects psychiatriques de la douleur somatique. In: La Douleur et les Douleurs (Ed. by Th. Alajouanine). Masson, Paris.

Mitchell, S.W., Morehouse, G.R. \& Keen, W.W. (1864) Gunshot Wounds and Other Injuries of Nerves. Lippincott, Philadelphia.

Montaigne, M.E. De (1580) Essais (Ed. by J.-V. le Clerc), Book 1, Chap. 40, p. 374. Garnier Freres, Paris, 1865.

Noordenbos, W. (1959) Pain: problems pertaining to the transmission of nerve impulses which give rise to pain. Elsevier, London.

ReAD, G.D. (1943) Childbirth Without Fear. Heinemann, London.

REIK, T. (1914) Couvade and the psychogenesis of the fear of retaliation. In: Ritual: Psychoanalytic Studies. Hogarth, London, 1931.

RIVERS, W.H.R. (1920) Instinct and the Unconscious. Cambridge University Press. 
Ruesch, J. (1946) Chronic disease and psychological invalidism: a psychosomatic study. Psychosom. Med. Monographs No. 9. Amer. Soc. Res. psychosom. Problems, New York.

SAUNDERS, C. (1963) The treatment of intractable pain in terminal cancer. Proc. roy. soc. Med. 56, 195.

SCHNEIDER, K. (1959) Clinical Psychopathology (Transl. by M. W. Hamilton). Grune \& Stratton, London.

Simpson, D.A., SAunders, J.M., Rischbieth, R.H.S., ReES, V.E., Burnell, A.W. \& Cramond, W.A. (1965) Experiences in a pain clinic. Med. J. Aust. 52, 671 .

Slater, E. (1965) Diagnosis of 'hysteria'. Brit. med. J. i, 1395.

Smith, R. (1963) The dynamics of pain. In: Problems of Dynamic Neurology (Ed. by L. Halpern). Jerusalem.

SMith, R. (1966) The use of pressure and chemical stimulation to investigate pain. Proc. roy. Soc. Med. 59, 73.

SPEAR, F.G. (1964) A study of pain as a symptom in psychiatric illness. M.D. thesis, Bristol University.

SPEAR, F.G. (1966) An examination of some psychological theories of pain. Brit. J. med. Psychol. 39, 349.

Srole, L., Langner, T.S., Michael, S.T., OPler, M.K. \& ReNNIE, T.A.C. (1962) Mental Health in the Metropolis: the Midtown Manhattan Study, Vol. 1. McGraw Hill, New York.

Stengel, E. (1960) Pain and the psychiatrist. Med. Press, 243, 23.

Szasz, T.S. (1957) Pain and Pleasure. A Study of Bodily Feelings. Tavistock, London.

Trethowan, W.H. \& Conlon, M.F. (1965) The couvade syndrome. Brit. J. Psychiat. 111, 57.

Truchaud, M. (1965) Étude des Variations du Seuil de la Douleur sous l'Influence de l'Altitude Simulée. Romand \& Beurel, Paris.

Veith, I. (1965) Hysteria: the History of a Disease. Chicago University Press.
Wallace, W. F. M., Loane, R.A. \& Quinn, J.T. (1963) A study of appendicectomies in Belfast in 1958. Ulster med. J. 32, 199.

Walters, A. (1961) Psychogenic regional pain alias hysterical pain. Brain, 84, 1.

WALTERS, A. (1963) The psychological aspects of bodily pain. Appl. Ther. 5, 853.

WeDDELL, A.G.M. (1962) Observations on the anatomy of pain sensibility. In: The Assessment of Pain in Man and Animals (Ed. by C. A. Keele and R. Smith). Livingstone, Edinburgh.

Weider, A., Mittelmann, B., Wechsler, D. \& Wolff, H.G. (1944) The Cornell Selectee Index: a method for quick testing of selectees for the armed forces. J. Amer. med. Ass. $124,224$.

WeIss, E. (1947) Psychogenic rheumatism. Ann. intern. Med. 26, 890.

Williams, J.C. (1852) Practical Observations on Nervous and Sympathetic Palpitation of the Heart, as well as on Palpitation, the Result of Organic Disease, 2nd edn. Churchill, London.

Wilson, H. (1938) Psychogenic headache. Lancet, i, 367.

WolfF, B.B. (1966) Drug studies in experimental and clinical pain. Symp. on Assessment of drug effects in the normal human. 74th Ann. Convention of Amer. Psychol. Ass., New York.

Wolff, B.B., Kantor, T.G., JaRvik, M.E. \& Laska, E. (1966a) Response of experimental pain to analgesic drugs. 1. Morphine, aspirin and placebo. Clin. Pharmacol. Ther. $7,224$.

WolfF, B.B., Kantor, T.G., Jarvik, M.E. \& Laska, E. (1966b) Response of experimental pain to analgesic drugs. II. Codeine and placebo. Clin. Pharmacol. Ther. 7, 323.

Wolff, H.G. (1948) Headache and Other Head Pain. Oxfor University Press, London. 